\title{
Para Além do Tempo de Emprego: o sentido do trabalho no processo de aposentadoria
}

\author{
Betina Magalhães Bitencourt ${ }^{1}$ \\ Shalimar Gallon ${ }^{2}$ \\ Mariana Klein Batista ${ }^{3}$ \\ Valmiria Carolina Piccinini ${ }^{4}$
}

\section{Resumo}

O trabalho é um meio essencial para a integração social e a autorrealização do indivíduo. Assim, observa-se que o momento da aposentadoria pode representar mudanças no sentido do trabalho. Essa transição pode ser encarada de modo positivo por aqueles que estão preparados para ela, entretanto, pode configurar-se em um período de incertezas e promotor de uma visão negativa dos dias que estão por vir. Dessa maneira, buscou-se analisar qual o sentido que o trabalho tem para os aposentados. O estudo consiste em uma pesquisa qualitativa com profissionais que estão se preparando para a aposentadoria e com aposentados vinculados à Fundação de uma empresa do Rio Grande do Sul. A coleta de dados foi realizada por meio de entrevistas, nas quais se buscou identificar quais as expectativas destas pessoas perante essa nova fase da vida. Buscou-se verificar como eles enfrentam essa ruptura, já que não há mais o trabalho para se identificar e criar laços sociais ligados a ele. Os entrevistados apresentaram reações positivas em relação à aposentadoria. Alguns entrevistados, porém, expressaram a necessidade de continuar atuantes no mercado de trabalho. Outro fator de satisfação apurado na análise das entrevistas foi a preparação para essa nova fase promovida pela empresa.

Palavras-chave: Aposentadoria. Centralidade do Trabalho. Sentido do Trabalho.

1 Mestre e Doutoranda em Administração pela Universidade Federal do Rio Grande do Sul - UFRGS. End.: Rua Washington Luiz, 855/422, Centro, Porto Alegre - RS. CEP: 90010-460 - Brasil. E-mail: betina_mb@yahoo.com.br.

2 Mestre e Doutoranda em Administração pela Universidade Federal do Rio Grande do Sul - UFRGS. End.: Rua Washington Luiz, 855/422, Centro, Porto Alegre - RS. CEP: 90010-460 - Brasil. E-mail: shalimargallon@hotmail.com.

3 Mestre em Administração pela Universidade Federal do Rio Grande do Sul - UFRGS. Administradora do Nós Coworking. End.: Av. Cristóvão Colombo, 545, prédio 02, $5^{\circ}$ andar, Floresta, Porto Alegre - RS. CEP: 90560-900 - Brasil. E-mail: marianakleinb@gmail.com. 4 Doutora em Economia do Trabalho e da Produção pela Universidade Pierre Mendes France UPMF - Grenoble II. Professora Associada da Universidade Federal do Rio Grande do Sul - UFRGS. End.: Rua Washington Luiz, 855/422, Centro, Porto Alegre - RS. CEP: 90010-460 - Brasil. E-mail: vpiccinini@ea.ufrgs.br.

Artigo recebido em: 25/02/2011. Aceito em: 27/07/2011. Membro do Corpo Editorial Científico responsável pelo processo editorial: Carlos Ricardo Rossetto.

(c) (i) () $\Theta$ Esta obra está sob uma Licença Creative Commons Atribuição-Uso. 


\section{Introdução}

O trabalho vem sofrendo mudanças no decorrer dos tempos, pois de atividade reservada aos participantes de camadas pobres da população, passou a atividade possível e necessária para aqueles em idade produtiva e com disposição física e mental para ele. Na esteira das mudanças sofridas pela sociedade, as formas de trabalho passaram por modificações, chegando ao que hoje se conhecem por trabalhos formais, informais e precários (ANTUNES, 2005). Em virtude destas mudanças, torna-se foco de discussão identificar qual a importância do trabalho na vida dos indivíduos. E o que se percebe, segundo Enriquez (1999), é que é possível realizar o trabalho de maneiras variadas e apresentar diferentes significados, mas que ainda tem papel fundamental na constituição do indivíduo e da sua socialização (ENRIQUEZ, 1999).

Com as inúmeras transformações e formas diversas de trabalho encontradas na atual sociedade brasileira, alguns autores argumentam que o trabalho pode estar caminhando para um fim. No entanto, para Sorj (2000, p. 2) o trabalho "[...] continua a ser um dos mais importantes determinantes das condições de vida das pessoas". Antunes (2005, p. 26) lembra ainda que

[...] da General Motors à Microsoft, da Benetton à Ford, da Toyota ao McDonald's, o mundo produtivo e de serviços ainda carece de uma dada forma de trabalho, seja ele material, produtivo ou imaterial.

Já Méda (1996) considera que vivemos em busca de uma abundância que não conseguimos atingir, mas para a qual trabalhamos na tentativa de chegar o mais perto possível, e que outras atividades (políticas, sociais, culturais) podem ocupar o lugar que antes era do trabalho, dependendo da ocupação, idade, legislação de um país.

Mesmo o trabalho tendo um papel central na vida dos indivíduos, após um determinado tempo, chega o momento da aposentadoria, benefício este que dá o direito de parar de contribuir com a Previdência e começar a receber seu benefício. Mas muitos permanecem trabalhando porque a aposentadoria não é suficiente para sua subsistência ou por não verem motivo para parar de trabalhar. Até por que na legislação brasileira que regulamenta os direitos daqueles com mais de 60 anos de idade é previsto também que os mesmos não 
podem ser discriminados em processos de seleção para emprego ou concursos, ou seja, prevê o direito à volta ao trabalho mesmo após a aposentadoria.

Diante dessas constatações e dos questionamentos acerca da importância do trabalho na vida daqueles que se aposentam, observa-se o trabalho como fator importante para a constituição dos indivíduos, para a criação e manutenção de laços sociais e para a manutenção da saúde mental (BASTOS, 1995; ENRIQUEZ, 1999; MORIN, 2001; DEJOURS, 2008). Desse modo, essa pesquisa tem o intuito de analisar de que forma eles estão encarando a aposentadoria $e$ qual o sentido que o trabalho tem nas suas vidas. Para tanto foram realizadas entrevistas semiestruturadas com futuros e atuais aposentados de uma empresa de economia mista do estado do Rio Grande do Sul. A organização foi escolhida por desenvolver um Programa de Preparação para a Aposentadoria (PPA) que está atrelado ao funcionamento do fundo de pensão para complementação da aposentadoria dos funcionários.

A seguir será apresentado o panorama do processo de aposentadoria no contexto brasileiro, seguido pela apresentação dos conceitos de sentido, significado e centralidade do trabalho. Na sequência serão apresentados os resultados e a análise das entrevistas, seguidos pelas considerações finais.

\section{Panorama da Aposentadoria no Brasil}

Após anos trabalhando durante oito horas diárias ou mais, chega o momento da aposentadoria por Tempo de Serviço ou por Idade. O benefício previsto em lei pelo Estado brasileiro assegura o direito a receber mensalmente um determinado valor em forma de gratificação, sendo que aqueles que a recebem deveriam fazer uso da mesma para subsistir, sem precisar continuar a desempenhar atividades profissionais. São contemplados com a aposentadoria os trabalhadores urbanos a partir de 60 anos de idade (no caso das mulheres) $e$ de 65 anos de idade (no caso dos homens), sendo que as trabalhadoras rurais têm direito a se aposentar aos 55 anos e os homens aos 60 anos (MINISTÉRIO DA PREVIDÊNCIA SOCIAL, 2009a). Outra opção para quem deseja se aposentar é optar pela Aposentadoria por Tempo de Contribuição ao Ministério de Previdência Social, que prevê 35 anos de contribuição do trabalhador e 30 anos de contribuição da trabalhadora (MINISTÉRIO DA PREVIDÊNCIA SOCIAL, 2009b). 
Em outubro de 2003 entrou em vigor o Estatuto do Idoso, que regulamenta, entre outras questões, aquelas ligadas à aposentadoria e ao trabalho dos aposentados. De acordo com a lei, é responsabilidade do poder público promover programas de preparação para a aposentadoria, fornecendo esse atendimento um ano antes de o trabalhador se aposentar. Da mesma forma, prevê que os aposentados e idosos não podem ser discriminados ao buscar trabalho, $e$ assegura-lhes o direito de trabalhar, desde que dentro de suas possibilidades físicas e psicológicas e aproveitando suas potencialidades (BRASIL, 2009).

De acordo com dados do IBGE (2009a), o Brasil é um país que passa, atualmente, por um processo de envelhecimento da população. Uma das razões dessa mudança na demografia nacional é a alteração ocorrida nas famílias na segunda metade do Século XX. Por volta da década de 1940 se observou uma diminuição nas taxas de mortalidade, acompanhada por um declínio das taxas de natalidade, possivelmente, decorrente das melhores condições de saúde da população.

Considera-se como Idoso aquele indivíduo que tem 60 anos de idade ou mais. Em 2006 havia aproximadamente 19 milhões de idosos no Brasil (IBGE, 2009a), sendo que para os homens a expectativa de vida chega, em média, 19,3 anos após os 60 anos, e para as mulheres 22,4 anos. Já os dados de 2008 indicam que o número de idosos aumentou para cerca de 21 milhões, e que a maior concentração de idosos está nos estados do Rio de Janeiro, em que $14,9 \%$ da população é composta por idosos, e do Rio Grande do Sul, em que chega a 13,5\% (IBGE, 2009b).

No que diz respeito ao seu padrão de vida, aproximadamente $11 \%$ deles tinha rendimento inferior a $1 / 2$ salário mínimo no ano de 2008. Mesmo assim, aproximadamente $23 \%$ eram apontados como pessoas de referência no domicílio ou na família, o que indica a importância econômica e social dos mesmos na sociedade. Estima-se, ainda, que em 2008 em torno de $85 \%$ dos idosos estavam aposentados no Brasil (IBGE, 2009b). Em dados anteriores, o IBGE (2002) apresentou resultados de que $62,4 \%$ dos idosos eram responsáveis pelos seus domicílios, o que representava cerca de $20 \%$ do total dos domicílios no país.

Como ainda são considerados provedores em uma grande parte das famílias brasileiras, os aposentados podem optar por ter uma atividade remunerada mesmo após a aposentadoria. Na literatura anglo-saxônica esse fenômeno é conhecido como bridge employment, ou seja, o ato de continuar trabalhando mesmo após a aposentadoria. Nesta categoria de trabalho estão incluídas di- 
ferentes formas de atividade, que podem ser em tempo integral, meio período ou trabalho temporário (SHULTZ, 2003, apud ZHAN et al., 2009). Os autores indicam que as principais razões para que o aposentado continue a trabalhar são a pressão financeira e a boa condição de saúde, que lhe dá condições para se engajar novamente no mercado de trabalho (ZHAN et al., 2009). Indicam, também, que em um estudo realizado nos Estados Unidos com mais de 12 mil aposentados entre 51 e 61 anos de idade os aposentados que realizam o bridge employment apresentam menores chances de terem doenças graves $e$ um menor declínio de capacidade de realização de atividades diárias, sendo que a saúde mental também se apresentou protegida naqueles aposentados que deram continuidade às suas atividades profissionais (ZHAN et al., 2009).

Em pesquisa realizada na região metropolitana de Curitiba, no estado do Paraná, em 2003, com 895 aposentados, constatou-se que 17\% deles trabalhavam e que somente cerca de $6 \%$ do total de entrevistados gostariam de estar trabalhando (FARIA, 2004). Isso pode ser um indicador de que, como mencionado anteriormente, muitos aposentados trabalham por necessidade, principalmente, seja em função de questões financeiras, seja para aproveitarem sua condição física.

Pimenta et al. (2008) realizaram estudo com aposentados para avaliar índices de qualidade de vida. Nos resultados, alguns dados chamam a atenção, como o fato de que os aposentados com mais idade apresentaram índices de qualidade de vida mais altos. Também foi ressaltado que aqueles que mantêm ocupação profissional após a aposentadoria foram os que apresentaram os melhores índices de qualidade de vida, independentemente do tempo de aposentadoria.

Atchley (1971; 1976; 1984; 1993 apud REITZES et al., 1996) definiu algumas características e particularidades do processo de aposentadoria. Segundo o autor, a aposentadoria envolve não apenas a perda do papel profissional, mas relaciona-se também com direitos considerados culturais, como o de ter aporte financeiro para que possa gerenciar seu tempo e sua vida. Outra peculiaridade do processo de aposentadoria estaria relacionada ao período de tempo que inicia na pré-aposentadoria e se estende até o fim da vida do indivíduo. Finalmente, a aposentadoria é distinta na forma que acontece e nas consequências que apresenta, pois essas podem variar de acordo com o passado do aposentado, suas condições de saúde prévias ao processo $e$ as circunstâncias envolvendo a aposentadoria em si. 
Assim, as mudanças em como se percebe a aposentadoria são significativas. Se no passado aposentar-se representava deixar de trabalhar, atualmente, é crescente o número de aposentados que se mantém em atividade, mesmo que em meio-período, tanto na busca de complementação para a aposentadoria quanto por prazer em manter-se trabalhando (FRANÇA, 2009). Frente a esses dados procura-se saber o sentido que pessoas em processo de aposentadoria ou já aposentadas atribuem ao trabalho.

\section{Sentido e Centralidade do Trabalho}

Para entender o sentido do trabalho busca-se, primeiramente, compreender o que é trabalho para os indivíduos. Para Dejours (2008), o trabalho tem um caráter utilitário e também se apresenta como a afirmação da identidade do indivíduo por meio das atribuições individuais inseridas pelo mesmo na realização da tarefa. De acordo com Enriquez (1999), o trabalho é constituinte do ser humano. O trabalho também pode ser analisado como forma de identidade dos indivíduos, o qual define a personalidade dos trabalhadores e as remodela, estabilizando suas personalidades e seus desejos, colocando-os na realidade e possibilitando que se instaure a temporalidade na qual o indivíduo se desenvolve (ENRIQUEZ, 1999).

Embora o trabalho tenha um papel central na vida das pessoas e que esse auxilie na formação da sua identidade, discute-se hoje que esse esteja passando por uma reconfiguração de conceito. Isso está relacionado à flexibilização, à informalização e à precarização do trabalho, entre outros fatores que vêm surgindo com as novas formas da organização do mesmo (LEITE, 2008).

Alguns pesquisadores, como Kovács (2002), Toledo (2000) e Antunes (2002), observam que, por mais que possam emergir outras formas de organização, o trabalho não deixará de ser central na vida do indivíduo, pois ele pode assumir diversos sentidos ou até mesmo significados. Segundo o modelo de Hackman e Oldham (1975), um trabalho que tem sentido é importante, útil e legítimo para aquele que o realiza e é influenciado por: (i) a variedade das tarefas; (ii) permitir a realização de algo do começo ao fim, com um resultado tangível, identificável; (iii) ter um impacto significativo sobre o bem-estar ou sobre o trabalho de outras pessoas, seja na sua organização, seja no ambiente social; (iv) a autonomia; e (v) o feedback. 
O sentido do trabalho, de acordo com as pesquisas do Meaning of Work International Research Team - MOW (1987) é definido pelo significado (no nível individual, coletivo e social do trabalho), pela utilidade da tarefa executada para a organização a qual pertence, a autorrealização e a satisfação, o sentimento de desenvolvimento e evolução pessoal e profissional e a liberdade e autonomia para a execução das tarefas. Dentro desse contexto, Morin (2001), que baseou seus estudos nas pesquisas do MOW (1987), compreende que o sentido do trabalho é composto pelo significado, pela orientação e pela coerência do trabalho. $\mathrm{O}$ significado corresponde às representações que o sujeito tem de sua atividade, assim como o valor que lhe atribui, a orientação é o que o indivíduo busca no trabalho e o que direciona suas ações e a coerência é o equilíbrio que o trabalhador espera de sua relação com o trabalho. Portanto, entende-se que um trabalho com sentido é aquele que realiza, satisfaz e estimula o indivíduo para o desempenho de suas tarefas.

Em uma pesquisa com estudantes de administração, Morin (2001) observou que trabalho é um meio de emancipação. Nesse estudo, os fatores que influenciam no trabalho são o salário, as atividades que possibilitam desenvolver o potencial e fortalecer a identidade dos indivíduos, as relações construídas no trabalho, os resultados obtidos que permitem às pessoas darem sua contribuição à sociedade e um sentido à sua existência. Nessa pesquisa, a autora questionou administradores que trabalham na área de recursos humanos sobre o que eles mais sentiriam falta se parassem de trabalhar. As respostas se referiam ao fato de sentir falta de algo para fazer, ser produtivo, sentir-se útil, ter dignidade pessoal, manter as relações com os outros, sentimento de fazer parte de um grupo e o salário.

Apesar do grupo de respondentes ser diferente, há uma similaridade nas respostas, tanto do grupo que procura encontrar sentido no trabalho, como dos que falaram do que mais sentiria falta se parassem de trabalhar. Por fim, conclui-se que um trabalho que tem sentido é o trabalho que é feito de maneira eficiente e leva a alguma coisa, é intrinsecamente satisfatório, moralmente aceitável, fonte de experiências de relações humanas satisfatórias, um trabalho que mantém ocupado e garante a segurança e a autonomia (MORIN, 2001). Nesse último fator foi ressaltado que, embora o salário seja associado a elementos de prestígio, a autora destaca que nesse estudo ele remete aos elementos de segurança e de independência. 
Nessa pesquisa, foi levantado que um trabalho com sentido é uma atividade programada, que estrutura o tempo, dando sentido aos períodos de atividade e sem atividade (folgas, finais de semana, férias). Enriquez (1999) corrobora com esse argumento quando ressalta que o trabalho permite instaurar a temporalidade. Quando não se tem temporalidade, não se reconhece mais o indivíduo, pois não se sabe mais o que se tem para fazer, pois as atividades simplesmente perdem o sentido.

Piccinini et al. (2005), em pesquisa com profissionais de Recursos Humanos que faziam curso de formação continuada, apresentam três dimensões para classificar o trabalho e seus sentidos: a individual, a organizacional e a social. Na dimensão individual, o trabalho engloba valores morais (éticos) da pessoa, é prazeroso, possibilita valorização, desenvolvimento e crescimento, a pessoa sabe com que objetivo o mesmo está sendo realizado e acredita naquilo que está fazendo. $\mathrm{O}$ fator financeiro é referido como complementar e não essencial para que o trabalho faça sentido. Na dimensão organizacional, são relacionados fatores ligados à utilidade, organização do trabalho e relações interpessoais no ambiente de trabalho. A existência de desafios na execução da atividade é um aspecto importante, pois a partir do momento em que a tarefa se torna rotineira, burocrática, operacional e incapaz de instigar o trabalhador, o trabalho deixa de ter sentido para o indivíduo. Ainda na dimensão organizacional, para que um trabalho tenha sentido, ele deve ser realizado em um ambiente agradável, que proporcione relações construtivas. $\mathrm{Na}$ dimensão social, o trabalho com sentido deve ser capaz de contribuir e ser útil para a sociedade.

Para Bastos (1995) encontrar sentido para o trabalho proporciona a construção da identidade pessoal e social do indivíduo por meio das tarefas que executa, possibilitando que se identifique com aquilo que realiza. Percebe-se, assim, a importância que o emprego tem na vida do indivíduo e como a sua realização está relacionada com o sentido que o trabalho tem para cada pessoa. Desse mesmo modo, salienta-se que além de fazer parte da construção da identidade, o trabalho contribui para dar sentido à vida da pessoa. Uma vida dotada de sentido fora do trabalho provém de uma vida cheia de sentido dentro do trabalho (ANTUNES, 2000).

Dessa maneira, ao analisar o sentido que o trabalho tem na vida da pessoa, também pode se perceber o quão central ele é na vida dos indivíduos. Assim, a centralidade do trabalho refere-se ao grau de importância conferido ao trabalho durante a vida. Além disso, essa importância pode diferir entre as 
fases da vida do trabalhador, a chamada centralidade relativa do trabalho. Essa centralidade é influenciada por cada ciclo e mede a relação do trabalho com outros aspectos importantes da vida dos indivíduos. Assim, é normal que a mesma pessoa dedique-se ao trabalho de maneira diferente durante cada etapa da sua vida profissional, podendo ser movido pela necessidade ou, simplesmente, pelo apreço à atividade exercida (MOW, 1987; TOLFO; PICCININI, 2007).

No entanto, como consequência das inúmeras transformações que o mundo do trabalho vem sofrendo, as relações de trabalho acabam sendo conduzidas de maneira diferente. Essas são vivenciadas por uma geração de trabalhadores marcada por inseguranças, pelo efêmero e pelas descontinuidades, acarretando uma série de mudanças no conceito da centralidade do trabalho na vida das pessoas. Mas isso não quer dizer que o trabalho tenha perdido sua centralidade perante essa nova geração, visto que o trabalho também tem o sentido de sobrevivência para a grande maioria desta geração. (TELLES, 2006; TOMIZAKI, 2006 apud LEITE, 2008).

Ainda, pesquisas como a de D'Acri (2003), comprovam que mesmo em atividades consideradas insalubres, como na fabricação do setor têxtil de amianto, os trabalhadores conseguem vislumbrar um sentido no seu trabalho. $\mathrm{E}$, consequentemente, o ofício também pode tornar-se central na vida dos indivíduos, a partir do momento em que representa a garantia da sua sobrevivência. Mais ainda se a atividade representar uma referência na definição da identidade social do trabalhador e que, na sociedade salarial, remete não só a um sentido de subsistência, mas de acesso à educação, à cultura e ao status social (HIRATA; PRÉTECEILLE, 2002).

Contudo, acompanhando os estudos que remetem a uma centralidade cada vez maior do trabalho na vida dos trabalhadores, há autores que apresentam novas concepções sobre o trabalho. Segundo Gorz (1995, p. 16), não se vive mais em uma sociedade de produtores, pois

[...] o trabalho não é mais o principal cimento social, nem o principal fator de socialização, nem a ocupação principal de cada um, nem a principal fonte de riqueza e de bem-estar, nem o sentido e o centro de nossas vidas.

Afirma que não há uma centralidade do trabalho remunerado, pois este não representa mais a fonte principal de identidade e sentido na vida das 
pessoas. Offe (1989), por sua vez, destaca três aspectos que corroboram com essas ideias: a heterogeneidade das formas de trabalho, o declínio da "ética do trabalho" e as mudanças da importância do trabalho na vida de cada pessoa, provocadas pelos constantes deslocamentos ocupacionais no decorrer da carreira profissional.

Antunes (2002) opõe-se a esses argumentos e afirma que não se pode concluir que há uma perda na centralidade do trabalho no universo de uma sociedade produtora. Mesmo que haja uma tendência a uma maior intelectualização do trabalho fabril ou um desenvolvimento do trabalho qualificado, tendo como consequência uma subproletarização dos trabalhadores, não há uma perda da centralidade da categoria trabalho na sociedade contemporânea.

A redução do tempo de trabalho, bem como a diminuição do trabalho manual e o incremento do trabalho intelectual afirmam a lei do valor ao se considerar a centralidade do trabalho. Portanto, o que acontece é que o trabalho não perde importância, mas o significado do que é trabalhar é que se modifica. Essa modificação ocorre quando os limites entre trabalho e não-trabalho se tornam difusos, com o aumento da flexibilidade nas relações de trabalho e do individualismo entre as pessoas (TOLEDO; HERNANDEZ, 2000; ANTUNES, 2002). Devido às discussões acerca da centralidade do trabalho e da importância do mesmo para a constituição psíquica das pessoas, cabe visualizar os efeitos da aposentadoria para o trabalhador. A aposentadoria seria o momento em que se deixa de trabalhar cotidianamente, com horários pré-fixados, recebendo salário por isso, o que pode trazer desgaste na vida do indivíduo.

Alvarenga et al. (2008) apontam alguns fatores que podem ser causadores de uma reação negativa à aposentadoria, como a perda do vínculo social que havia sido constituído em torno das relações profissionais e a diminuição da renda, que levam a uma mudança de estilo de vida. Porém, o ponto principal apontado pelas autoras como promotor de negatividade seria a falta de planejamento para aquele momento de transição. Já Reitzes et al. (1996) indicam que as reações negativas acontecem mais comumente naqueles grupos de aposentados que já traziam históricos de depressão ou problemas de baixa autoestima.

Tendo por base a discussão já apresentada, nesta pesquisa busca-se verificar quais são os possíveis efeitos da aposentadoria para um grupo de trabalhadores aposentados ou em via de aposentar-se. Na sequência será apresentada a pesquisa conduzida nesse sentido. 


\section{Características da Pesquisa}

O trabalho realizado é de caráter qualitativo, que busca por meio de depoimentos dos entrevistados analisar o lado subjetivo da aposentadoria e transformar em dados relevantes (DEMO, 2000). Os dados foram coletados por meio de um roteiro de entrevistas semiestruturado e baseado no referencial teórico abordado. As entrevistas possibilitam uma maior interação entre entrevistador-entrevistado, pois permitem ao entrevistador compreender e capturar a perspectiva dos entrevistados. As entrevistas foram gravadas com a permissão dos entrevistados para posterior transcrição. Foi utilizada a análise de conteúdo com o intuito de descobrir, predizer e ir além das transparências dos dados (BARDIN, 2004).

A pesquisa foi realizada em uma empresa de economia mista, fundada em 1966 da qual o Estado do Rio Grande do Sul é o acionista controlador. Foi feita a escolha por essa organização pelo fato dela ter um programa estruturado de Preparação para Aposentadoria, que ocorre anualmente desde o ano de 1984 e é organizado pela área de Serviço Social da empresa em parceria com a Fundação da mesma, que tem como objetivo administrar os Planos de Previdência dos funcionários, visando garantir o pagamento de benefícios aos mesmos. Hoje esta Fundação auxilia aproximadamente 17 mil pessoas, entre participantes e dependentes. Já a organização, conta, atualmente, com cerca de cinco mil funcionários, sendo que a maioria tem grau de formação médio ou superior. A entrada na empresa se dá por meio de concurso público e, conforme informações das organizadoras do evento, os funcionários tendem a permanecer na empresa por décadas, sendo que boa parte deles tem nela seu primeiro e único emprego, deixando a empresa apenas quando se aposentam. A empresa pesquisada apresenta algumas características particulares, dentre as quais uma política muito forte e exigente no tocante ao cumprimento dos horários de trabalho, e a estabilidade para seus funcionários.

A coleta de dados foi realizada em um evento promovido pela empresa, no período de 14 a 18 de dezembro de 2009, na cidade de Porto Alegre. Esse evento reuniu 45 participantes, entre funcionários e acompanhantes, de todo o estado do Rio Grande do Sul e teve o intuito de esclarecer as dúvidas sobre a aposentadoria, auxiliar no preparo dos trabalhadores para enfrentar o período de mudanças e promover a conscientização a respeito da aposentadoria em seus aspectos técnicos e pessoais. Cabe enfatizar que os entrevistados fazem parte de um caso específico de uma empresa que possibilita estabilidade para os seus funcionários, além de possuir um fundo de pensão que permite que 
recebam complementação da aposentadoria, permitindo que mantenham o mesmo padrão de vida de quando estavam na ativa.

Em um primeiro momento, foram realizadas entrevistas exploratórias com duas funcionárias que fazem parte da organização do evento a fim de esclarecer o seu funcionamento e a sua programação. Em relação aos aposentados, eles foram divididos em três grupos: (i) Grupo 1: pessoas que estão prestes a se aposentar; (ii) Grupo 2: pessoas que estão aposentadas há pouco tempo (até 3 anos); e (iii) Grupo 3: pessoas que estão aposentadas há mais tempo (de 3 anos em diante), conforme mostra o Quadro 1. Essa distinção de tempo ocorreu em função de que, passados três anos de aposentadoria, o público em questão já teria vivenciado as mudanças decorrentes da maturidade do processo e teria se estabilizado nessa nova etapa da vida. Como o evento permite a participação do Grupo 1 e 2, os entrevistados foram escolhidos de forma aleatória, conforme demonstravam disponibilidade para responder as perguntas. Em relação aos entrevistados do último grupo, apesar de poderem participar do evento, não foram localizados participantes aposentados há mais de três anos. Assim, buscaram-se indicações com os participantes de aposentados que preenchessem os requisitos e pudessem participar da pesquisa. Foi realizado contato por telefone explicando o objetivo da pesquisa e a razão da indicação para a entrevista, sendo que as três primeiras pessoas indicadas aceitaram participar da pesquisa e, assim, as entrevistas foram realizadas, duas no evento e uma na residência do entrevistado.

\begin{tabular}{|l|c|c|l|l|}
\hline Entrevistado & \multicolumn{1}{|c|}{ Faixa Etária } & \multicolumn{1}{|c|}{ Sexo } & \multicolumn{1}{|c|}{ Situação } & Grupo \\
\hline Entrevistado A & Entre 60 e 65 anos & Masculino & $\begin{array}{l}\text { Não aposentado - Falta 1 mês } \\
\text { para se aposentar. }\end{array}$ & Grupo 1 \\
\hline Entrevistado B & Entre 55 e 60 anos & Masculino & $\begin{array}{l}\text { Não aposentado - Faltam 6 } 6 \\
\text { meses para se aposentar. }\end{array}$ & Grupo 1 \\
\hline Entrevistado C & Entre 50 e 55 anos & Feminino & $\begin{array}{l}\text { Não aposentada - Falta 1 mês } \\
\text { para se aposentar. }\end{array}$ & Grupo 1 \\
\hline Entrevistado D & Entre 50 e 55 anos & Feminino & Aposentada - Há 1 mês. & Grupo 2 \\
\hline Entrevistado E & Entre 60 e 65 anos & Feminino & $\begin{array}{l}\text { Aposentada - Há 11 meses } \\
\text { aposentada pelo INSS. Falta } \\
\text { umês para se desligar das } \\
\text { atividades profissionais na } \\
\text { empresa. }\end{array}$ & Grupo 2 \\
\hline Entrevistado F & Entre 60 e 65 anos & Feminino & Aposentada - Há 6 anos. & Grupo 3 \\
\hline Entrevistado G & Entre 55 e 60 anos & Feminino & Aposentada - Há 3 anos. & Grupo 3 \\
\hline Entrevistado H & Entre 65 e 70 anos & Masculino & Aposentado - Há 9 anos. & Grupo 3 \\
\hline
\end{tabular}

Quadro 1: Perfil dos entrevistados

Fonte: Elaborado pelas autoras deste artigo 
No total foram entrevistados oito funcionários aposentados ou em processo de aposentadoria. Além disso, as duas organizadoras do evento que auxiliaram na organização do programa elucidaram questionamentos das pesquisadoras e disponibilizaram material da empresa e do programa.

\section{Análise dos Resultados}

A análise dos resultados será apresentada pelos blocos que nortearam esse estudo: (i) caracterização do programa de aposentadoria acompanhado; (ii) aposentadoria; (iii) sentido, significado e centralidade do trabalho.

\subsection{Caracterização do Programa de Aposentadoria}

O Programa de Preparação para Aposentadoria (PPA) da organização estudada caracteriza-se como um curso de capacitação destinado aos funcionários que estão se aposentando ou pretendem fazê-lo. Esses profissionais podem levar consigo um acompanhante, pois o objetivo é também integrar a família neste processo de aposentadoria. O curso é realizado anualmente e é organizado pelo serviço social da Fundação da empresa pesquisada. Os funcionários são convidados para participar do evento por meio de um comunicado na intranet da empresa, disponibilizado pela Superintendência de Recursos Humanos da mesma. Eles precisam efetuar uma inscrição e, após a seleção, os escolhidos são convocados a comparecer ao evento. Essa seleção se dá pela limitação de vagas no local do evento e tem como critério o tempo que falta para a aposentadoria do funcionário (o mais próximo, até dois anos).

No PPA, os participantes têm acesso aos mais variados conteúdos, distribuídos em uma semana com intensa programação, tais como: palestras com médico geriatra sobre os aspectos médicos do envelhecimento, com economista sobre finanças pessoais, nutricionista que trata sobre nutrição e qualidade de vida, com administradora que aborda as possibilidades de realização de trabalho voluntário, com educador físico, terapeuta familiar entre outros profissionais destinados a prover informações relevantes sobre essa nova fase da vida dos futuros aposentados e refletir sobre a mesma.

Além disso, há uma programação recreativa e cultural, como passeios, apresentação teatral e um filme que trata sobre a questão da aposentadoria. 
Também é feita uma visita à sede da Fundação, para que sejam feitos os cálculos e dada uma orientação individual sobre as vantagens e desvantagens de solicitar a aposentadoria em determinada época.

Um dos aspectos positivos do evento é a sua gratuidade, incluindo transporte, hospedagem, alimentação e a possibilidade de levar um acompanhante (esposa, marido ou companheiro/a) para participar das atividades juntamente com os demais funcionários, também com todos os custos pagos pela instituição. Outro aspecto positivo advém da participação do companheiro do funcionário que entra em contato durante o curso com a importância do apoio familiar. As assistentes sociais responsáveis pelo evento apontam que a rede de apoio criada pela famîlia neste momento possibilita enfrentar as mudanças que estão por vir de forma mais tranquila e positiva, já que as mesmas podem trazer um momento de ansiedade para o recém-aposentado. Aponta-se ainda como aspecto positivo o fato de que são convidados a participar do PPA todos os funcionários independentemente de cargo e/ou ocupação na empresa. Dentre os aspectos negativos, é possível citar o fato de que há um limite de vagas para participantes, imposto pela disponibilidade de quartos no hotel escolhido para o evento, podendo ocorrer de alguns não conseguirem participar do mesmo. Além disso, pode ocorrer de que às vezes o evento não tenha um grande alcance, pois ele não tem caráter obrigatório, sendo assim, o número de interessados pode variar bastante.

\subsection{Aposentadoria}

Em relação à aposentadoria, os entrevistados consideram que é somente mais uma etapa da vida e eles têm grandes expectativas em relação a esse novo momento. Além disso, é enfatizado, tanto por eles quanto pelas organizadoras do programa de preparação, que eles são muito novos e que devem, agora, vivenciar o que não tinham tido oportunidade antes, mostrando que enquanto eles trabalhavam não tiveram a oportunidade de realizar outras atividades.

Eu não vejo assim que se aposentar é morrer [...] eu vou partir para uma outra fase aposentada, mas em atividade em outras coisas: minha família, minha casa, meus amigos. Tenho outras coisas para curtir (Entrevistada E).

Eu imaginava mais ou menos o que eu tô passando, tô num período de transição, que eu esperava mesmo... e projetos, de 
viajar, viajar com meus amigos, encontrar minhas amigas... porque isso aí é vida, é uma oportunidade, eu acho. Porque se eu estivesse trabalhando eu não ia poder fazer isso (Entrevistada D).

Olha, aposentadoria é uma parte da vida e é uma parte feliz (Entrevistada G).

Apesar dos aposentados não terem sido questionados a respeito da importância do evento que estava sendo realizado, do programa de preparação e do fundo de pensão, todos, em algum momento da entrevista, abordavam como o programa e o evento, em específico, ajudaram na sua aposentadoria Esse tipo de preparação é o que Atchley (1971; 1976; 1984; 1993 apud REITZES et al., 1996) refere quando explica que deve existir uma preparação para a aposentadoria. Além disso, foi ressaltada a importância das pessoas se planejarem para tal e que isso seja pensado desde o momento em que se escolhe a profissão na juventude.

Eu aconselhei todos os colegas que eu podia a fazer a preparação... se tu não tem nada preparado é complicado, né? Tu tem que ter um projeto, tem que ter tuas coisas (Entrevistada $\mathrm{G}$ ).

Quando eu me aposentar já tenho projetos. Faz três anos que eu me planejei para a minha aposentadoria [...] Eu já estou saindo, estou pronto, estou tranquilo. Totalmente. Quando eu completei 50 anos [...] Aí eu fui ver com a família o que eu podia fazer. Ah vou montar uma imobiliária na praia. O que eu não quero é voltar a bater ponto. [...] Eu fui fazer o curso do $\mathrm{CRECI}^{5}$, fiz outro curso imobiliário e agora estou vendo outro curso (Entrevistado B).

Se não tivesse a complementação da Fundação não teria como ficar sem trabalhar (Entrevistada G).

Hoje eu sou melhor remunerada porque eu paguei antes, então foi tudo planejado [...] tenho colegas que não pagaram a Fundação e aí hoje estão só com o $\operatorname{INSS}^{6}$ (Entrevistada F).

5 Conselho Regional dos Corretores de Imóveis.

6 Instituto Nacional do Seguro Social (INSS) é uma autarquia do Governo Federal do Brasil que tem como objetivo reconhecer e conceder direitos aos seus segurados. A renda transferida pela Previdência Social é utilizada para substituir a renda do trabalhador contribuinte, quando ele perde a capacidade de trabalho, seja pela doença, invalidez, idade avançada, morte e desemprego involuntário, ou mesmo a maternidade e a reclusão. Disponível em: <http://www.previdenciasocial.gov.br/index.php>. Acesso em: $1^{\circ}$ out. 2010. 
Embora França (2009) destaque o crescimento do número de aposentados que se mantêm em atividade, alguns dos resultados dessa pesquisa vão de encontro a essa informação. O que pode ser observado é que os entrevistados recebem, em sua maioria, um valor elevado de aposentadoria, o que pode estar relacionado ao fato de uma parcela deles não pretender continuar trabalhando. Entretanto, a necessidade que esses têm de fazer atividades que preencham o tempo livre é notável. O que foi observado é que eles têm vários projetos e através deles continuarão a desenvolver atividades, nas quais buscam reconhecimento, laços sociais e ocupação para o tempo vazio. Assim, se pode perceber que a dificuldade de "ficar parado" é grande, por isso eles buscam em outras atividades preencher o tempo livre que antes era destinado ao trabalho remunerado. Percebe-se que o trabalho, além da remuneração, tem grande importância no cotidiano das pessoas e quando elas se aposentam existe uma necessidade de encontrar outras atividades.

Vale ressaltar que o entrevistado com menor renda (em torno de dois mil reais por mês) pretende continuar trabalhando, embora tenha relatado que isso se deve ao fato de "não conseguir ficar parado". Além disso, ele observou que pensa no futuro dos filhos que ainda tem que fazer faculdade, o que pode ser um dos motivos para continuar exercendo um trabalho remunerado e não outras atividades, como trabalhos manuais, aulas de tênis, viagens, como os outros entrevistados. Assim, percebe-se que a remuneração que a pessoa vai receber na aposentadoria pode influenciar na escolha de continuar ou não trabalhando.

A gente não para em casa, nem eu e nem ela [a sogra de 93 anos, que também faz trabalhos manuais], porque a gente tá sempre envolvida com esse trabalho manual, criando, fazendo coisas bonitas. Então é um outro enfoque, mas é uma atividade, é um trabalho que gratifica porque tu faz coisas bonitas (Entrevistada G).

A separação foi uma coisa doída, assim como a aposentadoria [...] aí eu fui pra academia, comecei a dançar, comecei a tocar piano de novo [...] entrei num coral [...] tenho pintura, caminho [...] fui atender um asilo [...] eu sou uma pessoa muito ativa... e esse último ano eu tinha serviço [laudos para empresa] [...] eu me casei de novo, os filhos voltaram... então agora em outubro que eu parei e tive pela primeira vez férias [...] e aí pensei 'ah, que bom, férias, aposentada' [...] mas agora, que eu tô fazendo 61 anos (Entrevistada F). 
Eu tive que esperar um pouquinho porque eu me aposentei primeiro, a minha esposa se aposentou depois. Eu fiquei meio dependente, eu não podia fazer grandes coisas porque tinha que esperar ela. Ela trabalhava bastante [...] eu ia pra academia, a tarde ficava muito no computador, vendo vídeos, saía ia pro clube, jogar tênis. Na época eu não sabia jogar tênis, aí fui para academia para entrar em forma e depois aprendi a jogar. Lá eu tenho a parceria com o pessoal do tênis e cada vez aumenta mais (Entrevistado $\mathrm{H}$ ).

Dessa forma, compreende-se que a aposentadoria é mais uma etapa da vida e que há grandes expectativas em relação a esse novo momento. Essas expectativas referem-se a viagens, cursos, e momentos de lazer com a família, os quais podem estar relacionados à necessidade de se ter outra ocupação na sua vida, algo que possa preencher a lacuna e o tempo que o emprego deixou. Observou-se a importância de programas de preparação para aposentaria, assim, também como o fundo de pensão para complementar a renda. Além disso, foi ressaltada a importância das pessoas de se planejarem para a aposentadoria, o que pode amenizar as dificuldades encontradas nessa nova etapa.

\subsection{Sentido do Trabalho}

Conforme as definições acerca de trabalho dadas por Dejours (2008), Méda (1996) e Enriquez (1999), o trabalho, além de seu caráter utilitário, tem também caráter de integração social e desenvolvimento da identidade. Nas entrevistas, observou-se que o trabalho tem as mesmas configurações citadas pelos autores, como sendo algo fundamental para a vida e constituição do sujeito e dos laços sociais.

Trabalho é vida, né? É vida... eu acho o trabalho muito importante, o dinheiro é muito importante porque é a sobrevivência. O que seria de nós sem o dinheiro? Porque ele é que proporciona o bem-estar todo pra nós. Mas o trabalho é muito mais do que o dinheiro, pelo lado... o trabalho é que deixa a pessoa... como é que eu posso te dizer? Eu acho que o valor da pessoa é o valor pelo trabalho (Entrevistada D). 
Trabalho, a gente trabalha na empresa, trabalha em casa. Todo serviço é trabalho (Entrevistada E).

O trabalho é integração, coleguismo, amizade (Entrevistado B).

O sentido do trabalho, de acordo com Hackman e Oldham (1975), MOW (1987) e Morin (2001), passa pelos níveis individual, coletivo e social do trabalho. Segundo os autores para ter sentido o trabalho precisa trazer satisfação, autorrealização, ter impactos positivos na vida das pessoas, precisa trazer autonomia, entre outras características. Os entrevistados, em sua maioria, citaram a satisfação, autonomia e a autorrealização como fatores importantes para o sentido do trabalho.

Ele é importante porque além de trazer satisfação, ele dá aquele senso de utilidade pra tua vida. E ele gera todo um círculo de amizades, de pessoas, de trabalho e outros correlatos que te fazem ter uma boa qualidade de vida (Entrevistado A).

Trabalho te dá autonomia, autoestima, satisfação... enfim, complementa a pessoa, né? [...] Além de ter uma ocupação, de tu te relacionar com as outras pessoas (Entrevistada $\mathrm{C}$ ).

Em relação ao fator financeiro do trabalho, Piccinini et al. (2005) apontam em sua pesquisa que ele não traz sentido ao trabalho, e é sim um fator complementar. Durante as entrevistas, entretanto, o fator financeiro foi relembrado diversas vezes, seja para indicar que a aposentadoria é satisfatória devido à possibilidade de não ter obrigação de trabalhar mais, pois o fundo de pensão assegura a renda anterior, seja para indicar que a primeira finalidade do trabalho seria o salário e que as outras características seriam complementares ao fator financeiro. Nota-se, portanto, que a ausência da necessidade financeira libertaria do emprego, mas o trabalho continuaria a fazer parte da vida dessas pessoas. Além disso, os resultados mostraram que o trabalho é importante por também estar ligado ao status das pessoas (HIRATA; PRÉTECEILLE, 2002) e à independência financeira (MORIN, 2001).

Eu trabalho primeiro... claro, na verdade quando a gente é criança diz: 'eu vou ser isso, eu vou ser aquilo', pensando naquilo que for dar a maior renda. Só que por trás de uma 
renda tu preenche uma série de outras coisas que a gente não se dá conta, então tu preenche teu tempo, tu te satisfaz, tu vai atingindo os teus objetivos e vai crescendo até tu atingir algum status dentro da tua vida (Entrevistado A)

O trabalho é importante porque além de gerar uma renda, ele preenche aqueles vazios... tem que saber que tu tá preenchendo uma série de vazios, tu tem amizades, uma série de outras coisas que o trabalho te dá além de tu ganhar teu salário (Entrevistado A).

Do ponto de vista material, ele te dá subsistência, e também qualidade de vida [...] e a autoestima (Entrevistada F).

O sentimento de utilidade gerado pelo trabalho foi apontado pelos entrevistados como algo importante também para a construção do sentido do trabalho, de forma condizente àquilo tratado por Hackman e Oldham (1975), MOW (1987), Morin (2001) e Piccinini et al. (2005).

É realização, satisfação pessoal, prazer em trabalhar, e produzir... para que o resultado ele traga uma diferença para a minha empresa, pra mim, e pra família e até pra sociedade (Entrevistado A).

De acordo com o que foi apresentado pelos estudos do MOW (1987) de Hackman e Oldham (1975), Morin (2001), Piccinini et al. (2005), Hirata e Préteceille (2002), Dejours (2008), Méda (1996) e Enriquez (1999), observou-se que o trabalho é visto como promotor dos laços sociais e, assim, promotor da constituição do indivíduo. Nas falas dos entrevistados ficou claro que a autorrealização, a satisfação, o alcance dos objetivos entre outras características fazem do trabalho uma atividade considerada de fundamental importância para esse grupo de trabalhadores e aposentados.

Diversos autores discorrem a respeito do papel do trabalho na vida $e$ se este seria central para a constituição pessoal dos indivíduos (MOW, 1987; TOLFO: PICCININI, 2007; D'ACRI, 2003; HIRATA: PRÉTECEILLE, 2002). De forma contrária, há aqueles que indicam que a reconfiguração das formas de trabalho leva ao deslocamento da centralidade do trabalho e que esse trabalho não seria mais tão fundamental para os indivíduos (GORZ, 1995; OFFE, 1989). 
No entanto, as entrevistas mostraram que o trabalho tem um papel considerado importante para os trabalhadores daquela organização.

O trabalho pra mim é assim, fundamental [...] o trabalho é tudo (Entrevistada F).

$\mathrm{O}$ trabalho realiza a gente. Eu não imagino a vida sem trabalho (Entrevistada G).

Porque no trabalho... eu sou uma pessoa muito apegada, adoro os meus colegas, adoro. A minha vida foi ali. Principalmente porque eu tive a felicidade de ter muito tempo dentro de uma empresa. Então aquilo ali é uma segunda família da gente mesmo, é uma extensão da casa da gente, onde tu passa a maior parte do tempo. Embora tu nunca procure separar uma coisa da outra, de problemas e outras coisas, tu cria amizades grandes com pessoas que convivem contigo, que estão ali... tu cria muitos colegas e muitos amigos (Entrevistada D).

Pra mim, ele [o trabalho] era coisa mais importante que tinha... pra realização, pra autoestima, pra início de vida [...] era tão importante que só depois que eu consegui minha independência financeira que eu consegui me realizar com o sexo oposto (Entrevistada F).

É interessante observar que, apesar dos entrevistados enfatizarem a necessidade e importância de trabalhar, tanto pela necessidade financeira como pela necessidade de convívio social, muitos se sentem aliviados por não precisarem mais trabalhar. Isso pode estar relacionado a certa resistência à obrigatoriedade de trabalhar com horários controlados, o que trouxe para eles uma vontade e uma tranquilidade ainda maior de chegar à aposentadoria.

Na realidade ele [o trabalho] sempre foi colocado bem à frente assim, né, de preocupação, de cumprir os compromissos e tal... porque tudo isso dava satisfação e porque é uma coisa que eu gosto de fazer, né... então ele foi colocado... teve uma prioridade... e é tanto isso que eu tenho vontade de me aposentar... porque chegou um momento assim, que assim o horário é rígido, né? [...] então eu deixei de fazer muita coisa, inclusive de cuidar de mim [...] então agora é o momento que eu quero pensar nisso (Entrevistada $\mathrm{C}$ ). 
Eu quando venho trabalhar fico louco pra chegar no trabalho, aí a gente fica lá no trabalho... e seis pras cinco eu saio do trabalho e fico louco pra chegar em casa (Entrevistado A).

Hoje eu não uso relógio, estão todos na gaveta (Entrevistada F).

Também foi observado que, apesar de destacarem o quanto vão sentir falta do que o trabalho proporciona, estão muito felizes e/ou com muitas expectativas. É ressaltado que existe vida fora do trabalho e momentos que proporcionem satisfação.

O meu centro de vida já tá fora da empresa. Tá na família e nos filhos. (Entrevistado A)

Eu vou parar de trabalhar na empresa, mas eu não vou parar de viver a minha vida normal. (Entrevistada E)

Eu aceitei a condição de aposentado e gosto muito dela. (...) eu não acho nada como se eu tivesse uma missão para fazer. A missão hoje é fazer aquilo que eu gosto... é jogar, eu jogo tênis... é fazer nada, jogar tênis e conviver com meus amigos. (Entrevistado $\mathrm{H}$ )

Assim, por meio das entrevistas realizadas pôde-se observar aquilo que MOW (1987), Tolfo e Piccinini (2007), D’acri (2003), Hirata e Préteceille (2002) haviam descrito em seus trabalhos anteriores sobre o quanto o trabalho é central na vida do indivíduo. Foi possível, também, realizar uma comparação com a realidade desse grupo com pesquisas realizadas em contextos internacionais. Da mesma forma, corrobora-se a visão de Toledo e Hernandez (2000) e Antunes (2002) de que apesar das mudanças nas formas de trabalho, a importância do mesmo nas vidas das pessoas permanece.

Por fim, percebe-se que a aposentadoria é encarada com naturalidade e está sendo vista como positiva pelos entrevistados. Nessa fase, os indivíduos encontram tempo para fazer coisas que não faziam antes e estão sempre em busca de atividades para preencherem a lacuna que o trabalho deixou. Assim, percebe-se que o trabalho tem grande importância na vida das pessoas, seja pelo fator financeiro, satisfação, autonomia, autorrealização, laços sociais e constituição do sujeito. Isso remete ao fato de que as pessoas sentem que precisam estar envolvidas com alguma atividade para se sentirem úteis ou se sentirem 
parte de um grupo. Também se percebe que os entrevistados que possuem uma boa remuneração não pensam em continuar trabalhando para complementar a renda, mas buscam atividades para não ficarem completamente inativos e continuarem fazendo parte de grupos sociais.

\section{Considerações Finais}

A partir da pesquisa realizada pode-se considerar que a aposentadoria representa um momento de bastante expectativa e satisfação para os entrevistados. Essa é considerada como mais uma etapa da vida, em que aquilo que não puderam realizar enquanto trabalhavam, agora será concretizado. Nas entrevistas, observou-se que o trabalho tem as mesmas configurações desenhadas por pesquisas anteriores (MORIN, 2001; PICCININI et al., 2005) em relação às dimensões individuais, sociais e organizacionais. É importante ressaltar que, embora os entrevistados pertençam a um grupo específico de análise - trabalhadores de uma empresa pública, grande maioria com curso superior completo, com bons salários em comparação ao salário mínimo brasileiro, entre outras características peculiares - eles citaram a satisfação, autonomia e a autorrealização como fatores importantes para o sentido do trabalho.

As entrevistas mostraram que o trabalho representa um papel importante para os trabalhadores daquela organização. Entretanto eles consideram que chegou o momento de "curtir a vida" e que os laços sociais e reconhecimento que o trabalho proporcionava podem - e devem ser substituídos por outros afazeres. Com o fim do período de trabalho, pode haver uma perda de identidade, o aposentado pode sentir que sua vida está vazia, podendo até incorrer em vícios e problemas psicológicos (ALVARENGA et al., 2008; REITZES et al., 1996). Essa perda se daria devido à falta de planejamento para essa etapa e ao afastamento do trabalhador do grupo ao qual pertenceu durante um longo período de tempo, já que um dos componentes importantes do trabalho diz respeito ao contato social, capaz de trazer satisfação e contribuir na composição da identidade do trabalhador. No entanto, observou-se nas entrevistas que eventualmente o grupo social do ambiente profissional é substituído por outros grupos sociais, como aqueles formados em atividades de artesanato, trabalho voluntário ou esporte. O indivíduo, portanto, não deixa de se socializar, apenas 
transfere sua presença de um ambiente controlado por horários e outras normas para um onde não imperam essas obrigações.

Vale notar que os trabalhadores e aposentados entrevistados fazem parte de um grupo específico e com características bastante singulares, já que trabalham ou trabalharam em uma empresa, na qual além de estabilidade, dispõem de um fundo de pensão que complementa o valor pago como aposentadoria mensalmente pelo INSS. Dessa maneira, encaram o período da aposentadoria como algo prazeroso, que pode trazer possibilidades de novas atividades, sejam elas profissionais ou não. Também é importante observar que os entrevistados não demonstraram ter passado por problemas deste tipo na aposentadoria, embora eles soubessem de amigos de dentro da empresa e de outras empresas que ficaram doentes por não saber lidar bem com este momento.

Outro aspecto a ser apontado é o Programa de Preparação para a Aposentadoria, no qual se discutem as pressões do processo de aposentadoria e há a participação dos respectivos companheiros que passarão pelo processo juntamente com o aposentado, para que eles também sejam agentes de promoção do bem-estar e apoio no momento da transição para a aposentadoria. O direito à preparação para a aposentadoria é previsto em lei como função federal, estadual ou municipal, ou seja, todos os trabalhadores deveriam ter acesso a tal preparo. O programa promovido pela empresa em questão neste trabalho pode ser considerado um tanto peculiar, já que poucas são as empresas que oferecem cursos para preparar os trabalhadores para esta nova etapa da vida. Essa pode ser uma das razões pelas quais os entrevistados apresentam visão positiva acerca do período de aposentadoria e se sentem preparados para os momentos em que não terão mais atividades profissionais nas quais encontravam reconhecimento e realização pessoal. Nos relatos das entrevistas percebe-se que eles reconhecem que o período em que trabalharam foi proveitoso, que fizeram o melhor que podiam e que a aposentadoria é o momento merecido de descanso.

Dessa forma, compreende-se que o sentido que o trabalho tem é muito amplo e diverso para os indivíduos. Ele pode se manifestar de várias formas, que dependerão da organização em que a pessoa se encontra, dos colegas, das relações que são construídas, da família, da etapa da vida em que se encontra, de fatores financeiros, entre outros aspectos. Assim, tem-se a centralidade do trabalho como algo que difere, primeiramente, de acordo com a fase da vida 
de cada trabalhador, além de ser relacionada com o sentido que a pessoa dá ao seu trabalho.

Considerando o aumento da expectativa de vida da população brasileira, as organizações poderão ter bons resultados se tiverem a preocupação de ajudar na preparação para essa nova etapa, apesar de a lei prever a responsabilidade da preparação para os poderes públicos. Entretanto, ao se preparar um curso ou programa de preparação para a aposentadoria é importante ter em mente que não se pode simplesmente copiar modelos de outras empresas sem considerar o contexto da mesma e de seus trabalhadores. Além disso, o cuidado na adaptação para a realidade das organizações e dos indivíduos que as compõe pode trazer índices maiores de sucesso e diminuir os possíveis problemas enfrentados pelos trabalhadores que se aposentam.

Por fim, percebe-se que um fator que pode ser mais explorado em pesquisas futuras é o papel que o resultado financeiro do trabalho tem na vida dos trabalhadores e na sua percepção em relação ao trabalho. Também a importância de fazer essa pesquisa em outras organizações até mesmo para verificar se existem pessoas que tem dificuldade de enfrentar a aposentadoria e acabam tendo desajustes que podem ter repercussões físicas e emocionais no aposentado, pois, conforme já mencionado, a empresa pesquisada tem uma preparação para aposentadoria e fundo de pensão, o que pode amenizar os problemas dessa etapa da vida, mas seria interessante pesquisar em empresas que não tem esse apoio e observar como os funcionários lidam com essa nova fase da vida.

\section{Agradecimentos}

Agradecemos a Sra. Rosana Pozzobon, que permitiu esta pesquisa na Organização estudada, convidando-nos para participar do Evento mencionado e colaborando com a pesquisa por meio do fornecimento de dados e da indicação de entrevistados.

A todos os entrevistados, que se mostraram muito solícitos no desenvolvimento deste estudo.

Ao CNPq e à CAPES, pelo auxílio financeiro. 


\section{Beyond Working Time: the sense of work in the process of retirement}

\section{Abstract}

This work of theoretical nature investigates the contributions of the history of science to the production of scientific knowledge in the field of management and organizational studies. It was found in the study that the theories concerning the management and organizational studies are fallible and remain subject to a ongoing improvement or replacement. So, one should accept the idea of the need of constant transformation and improvement of knowledge. Became evident that the studies in administration and organizations witnessed a change of paradigm when classical school of management was questioned and added of new paradigms. In that way, that field of studies has become pluralistic, with conflicts among paradigms and average science, the questions concerning their research methodologies not being different at all. In this context, the history of science can present important lessons in showing that scientific revolution was not accepted peacefully, but by means of tough discussions and apparent contradictions. Several authors sought an approach between Social Ciences and Natural. Thus, the joint use of qualitative and quantitative methodologies is more and more present in management and organizational research granting a greater legitimacy to the different manners of approaching the theme. The debates about which is the best approach remain, in spite of a greater dialogue between these two chains of methodological thought being happening in the latest decades.

Key words: Qualitative methodology. Quantitative methodology. Administration. Organizational studies. History of science.

\section{Referências}

ALVARENGA, Líria Núbia et al. Repercussões da Aposentadoria na Qualidade de Vida do Idoso. Revista da Escola de Enfermagem da USP, São Paulo, v. 43, n. 4, p. 796-802, dez. 2009. 
ANTUNES, Ricardo. Adeus ao trabalho? Ensaio sobre as metamorfoses e a centralidade do mundo do trabalho. Perdizes: Cortez Editora, 1995; 2002.

ANTUNES, Ricardo. A Crise da Sociedade do Trabalho. In: O caracol e sua concha. São Paulo: Ed. Boitempo, 2005. p. 23-39.

BARDIN, L. Análise de conteúdo. 3. ed. Lisboa, Portugal: Edições 70, 2004.

BASTOS, A. V. B.; PINHO, A. P. M.; COSTA, C. A. Significado do trabalho: um estudo entre trabalhadores em organizações formais. Revista de Administração de Empresas, São Paulo, v. 35, n. 6, p. 20-29, 1995.

BRASIL. Lei n. 10.741, de $1^{\circ}$ de outubro de 2003. Disponível em: < http:// www.planalto.gov.br/ccivil/LEIS/2003/L10.741.htm>. Acesso em: 23 nov. 2009.

D'ACRI, Vanda. Trabalho e saúde na indústria têxtil de amianto. São Paulo em Perspectiva, São Paulo, v. 17, n. 2, p. 13-22, 2003.

DEJOURS, Christopher. Da psicopatologia à psicodinâmica do trabalho. Rio de Janeiro: Editora Fiocruz. Brasília: Paralelo 15, 2008.

DEMO, Pedro. Metodologia do conhecimento científico. São Paulo: Atlas, 2000.

ENRIQUEZ, Eugène. Perda do Trabalho, Perda da Identidade. In: NABUCO, Maria Regina; CARVALHO NETO, Antônio. (Org.). Relações de trabalho contemporâneas. Belo Horizonte: IRT da PUC de MG. p. 69-83, 1999.

FARIA, Décio L. M. P. Estou aposentado! E agora...? In: XXVIII Encontro da Associação Nacional de Pós-Graduação em Administração, 2004, Curitiba. Anais... 2004.

FRANÇA, Lucia Helena de Freitas Pinho. Influências Sociais nas Atitudes dos 'Top' executivos em face da Aposentadoria: um Estudo Transcultural. Revista de Administração Contemporânea - RAC, Curitiba, v. 13, n. 1, p. 17-35, jan./mar. 2009.

GORZ, André. Trabalho necessário e racionalidade econômica. Novos Rumos, São Paulo, n. 24, ano 10, 1995. 
HACKMAN, J. R.; OLDHAM, G. R. Motivation through the design of work: test of a theory. Organizational Behavior and Human Performance, v. 16, p. 250-279, 1976.

HIRATA, Helena; PRÉTECEILLE, Edmond. Trabalho, exclusão e precarização socioeconômica: o debate das ciências sociais na França. Caderno CRH, Salvador, n. 37 julho/dezembro de 2002.

IBGE - INSTITUTO BRASILEIRO DE GEOGRAFIA E ESTATÍSTICA, Diretoria de Pesquisas. Perfil dos idosos responsáveis pelos domicílios no Brasil - 2000. Rio de Janeiro: IBGE, 2002.

IBGE - INSTITUTO BRASILEIRO DE GEOGRAFIA E ESTATÍSTICA, Diretoria de Pesquisas. Indicadores Sociodemográficos e de Saúde no Brasil - 2009. Rio de Janeiro: IBGE, 2009a.

IBGE - INSTITUTO BRASILEIRO DE GEOGRAFIA E ESTATÍSTICA, Diretoria de Pesquisas. Síntese de indicadores sociais: uma análise das condições de vida da população brasileira - 2009. Rio de Janeiro: IBGE, 2009 b.

KOVÁCS, Ilona; Cómo hacer visible el trabajo que el discurso dominante oculta. In: Sociología del Trabajo, Nueva Época, n. 45, primavera, p. 25-51, 2002.

LEITE, Marcia de Paula. O trabalho e suas reconfigurações: conceitos e realidades. In: $32^{\circ}$ Encontro Anual da ANPOCS. GT: Trabalho e sindicato na sociedade contemporânea. Caxambu: 27 a 31 de outubro de 2008.

MEDA, Dominique. New perspectives on work as value. International Labor Review, Genebra - Suíça, v. 135 (1996), n. 6, 1996.

MINISTÉRIO DA PREVIDÊNCIA SOCIAL. Aposentadoria por Idade. [2009a.]. Disponível em: <http://www.previdenciasocial.gov.br/conteudoDinamico. php?id=15>. Acesso em: 20 nov. 2009.

MINISTÉRIO DA PREVIDÊNCIA SOCIAL. Aposentadoria por Tempo de Contribuição. [2009b.]. Disponível em: < http://www.previdenciasocial.gov.br/ conteudoDinamico. php?id=19>. Acesso em: 20 nov. 2009.

MORIN, Estelle M. Os sentidos do trabalho. Revista de Administração de Empresas - RAE, São Paulo, v. 41, n. 3, p. 8-19, jul./set. 2001. 
MOW International Research Team. The meaning of working. New York: Academic Press, 1987.

OFFE, Claus. Trabalho: a categoria sociológica chave? In: Capitalismo desorganizado. São Paulo: Brasiliense, 1989.

PICCININI, Valmiria C. et al. Quando trabalhar faz sentido. AGRH, Paris, setembro, 2005.

PIMENTA, Fausto Aloísio P. et al. Avaliação da qualidade de vida de aposentados com a utilização do questionário SF-36. Revista da Associação Médica Brasileira, São Paulo, v. 54. n. 1. p. 55-60, jan./fev. 2008.

REITZES, Donald C. et al. Does Retirement Hurt Well-Being? Factors Influencing Self-Esteem and Depression Among Retirees and Workers. The Gerontologist. v. 36, n. 5, p. 649-656, 1996.

TOLEDO, Enrique de la Garza; HERNANDEZ, Juan Manuel. Fin del trabajo o trabajo sin fin. In: Tratado Latinoamericano de sociología del trabajo. p. 755773. México, 2000.

TOLFO, Susana R.; PICCININI, Valmiria C. Sentidos e significados do trabalho: explorando conceitos, variáveis e estudos empíricos brasileiros. Psicologia \& Sociedade, Porto Alegre, v. 19, Edição Especial 1, 2007.

ZHAN, Yujie et al. Bridge Employment and Retirees' Health: a longitudinal investigation. Journal of Occupational Health Psychology, v. 14, n. 4, 374-389, 2009. 